\title{
European Communities - Measures Affecting the Approval and Marketing of Biotech Products
}

\author{
ROBERT L. HOW SE* \\ New York University School of Law \\ HENRIK HORN \\ Research Institute of Industrial Economics, Stockholm; Bruegel, Brussels; Centre for Economic Policy Research, \\ London
}

\begin{abstract}
The EC-Biotech dispute exposed the WTO dispute settlement system to a more challenging test than any previous dispute. Not only did the Panel have to take a stand on the limits of science, or technocratic regulatory controls, to protect against objective risk, but in this regard faced more complex issues than ever addressed before by an adjudicating body. The dispute also concerned an extremely charged political issue, partly because of inherent ethical sensitivities with regard to foodstuffs, partly due to public skepticism about the role of science, and partly due to a common public perception of the complaint as being driven by the interests of an untrustworthy industry. Because of these and other challenges, the Panel faced an almost impossible task. This paper discusses how the Panel addressed some of these issues. The recently (after our report was drafted) decided appeal in EC-Hormones Suspension is likely to reduce the significance for WTO jurisprudence of some of the Panel's findings in EC-Biotech, given the apparently different approach of the $\mathrm{AB}$ to fundamental interpretative issues under SPS concerning the meaning of risk assessment and precaution.
\end{abstract}

\section{Background}

In the EC-Biotech case, the United States, Argentina, and Canada challenged regulatory controls on genetically modified organisms (GMOs), imposed both by European Communities (EC) and some of its individual member states; these measures were based on a regulatory framework and policy decisions that existed through the 1990s until the recent putting into place of a new EC-wide GMOs regulation, including labeling and traceability requirements. ${ }^{1}$ Three kinds of

\footnotetext{
* Robert Howse acknowledges with gratitude the truly exceptional assistance and advice he received from Antonia Eliason in understanding the issues in this case, particularly those connected with the science in relation to GMOs. Eliason's own paper on the case, which we have cited, will soon be submitted for publication. Howse also learned much in conversations with his NYU colleague Dick Stewart, whose own forthcoming work offers important insights on this controversy. We are also grateful from comments by our discussant, Joseph H. H. Weiler.

1 European Communities - Measures Affecting the Approval and Marketing of Biotech Products. The Panel Report (WT/DS291/R, WT/DS292/R, and WT/DS293/R) was issued on 29 September 2006.
} 
measures were at issue: first of all, the so-called moratorium, a political decision of EC Members not to provide any more regulatory approvals for GMOs until a new, more rigorous regulatory approach could be agreed upon and put in place; secondly, individual delays or suspensions in the approval process for GMOs originating from the complainant states, which the complainants argued were attributable to the 'moratorium'; thirdly, member-state actions in banning GMOs that were acceptable under the EC regulatory scheme in effect at the time, based on the right under that scheme to take 'safeguards' at the member-state level even if the product was acceptable to the EC regulator.

The complainants alleged numerous violations of the WTO Agreement on the Application of Sanitary and Phytosanitary Measures (SPS Agreement), Technical Barriers to Trade (TBT) Agreement, and GATT (Article III:4, the national-treatment requirement). Most relevant to the disposition of the case by the Panel in its report are the following legal claims.

First of all, the Complainants argued that the individual delays and suspensions of approvals violated a procedural provision of the SPS Agreement requiring that regulatory decisions be made 'without undue delay'.

Secondly, two of the Complainants, Argentina and Canada, argued that various features of EC regulations and policies violated the national-treatment obligation in the GATT (Article III:4) because they provided 'less favourable treatment' to imported GMO products than to domestic non-GMO products. The underlying premise of this argument was that the GMO products in question were 'like' their non-GMO analogues within the meaning of 'like' in Article III:4 and therefore imports of the GMO products were entitled to be treated no less favorably.

Thirdly, with respect to the member-state 'safeguards', the Complainants argued, inter alia, that they violated provisions of SPS that required that SPS measures be based on scientific principles and not be maintained without sufficient scientific evidence (Article 2.2) and that such measures, to the extent that they were more protective than provided by international standards, be based on a risk assessment (Article 5.1). The measures in question were in respect of products for which risk assessments had been done, and on the basis of those risk assessments the EC regulator had found that the products in question were adequately safe to be approved in the EC. Thus, the Complainants argued, it is obvious that the member-state bans are not appropriately based on science.

The report in EC-Biotech approaches one thousand pages, a length that raises serious issues of Panel practice. How can a report of such length clearly communicate the meaning of the law and the approach to the facts in such a complex and yet controversial and important dispute? In any case, in this initial draft of our report we have selected a number of the issues broached by the Panel that we think deserve to be widely appreciated and the Panel's approach critically considered and debated. Many other issues merit legal and/or economic analysis.

To place the criticisms of the Panel that follow in some perspective, there are several underlying elements in the GMOs controversy that make its legitimate 
resolution through WTO dispute settlement proceedings inherently difficult or challenging. These complexities perhaps even require rethinking of the wisdom of using, in the text of SPS, 'science' as an arbiter in trade disputes concerning food safety. But the Panel is required to interpret and apply that text.

A first difficulty surrounds the limits of science, or technocratic regulatory controls, to protect against risk as perceived by real people. This is a theme developed in Justice Stephen Breyer's work, Breaking the Vicious Circle (Breyer, 1993). In the EC-Biotech dispute, the Panel was faced head on with this difficulty: where member states of the EC had taken 'safeguards', certainly in part because of lack of public confidence in claims about the safety of GMOs, the regulators in Brussels had already pronounced, based on 'science', that the products themselves were safe. As we shall argue, even if motivated by concerns in public opinion in the first instance, the 'safeguards', at least in some cases, were also based on a hard second look at the adequacy of the science underpinning the initial determination of safety at the EC level. For the EC to win this case, its trade lawyers would have to convince the Panel of the inadequacy of the scientific and regulatory judgments of their colleagues in another directorate of the Commission. In examining this aspect of the Panel's ruling below, we do consider that the Panel could have been more sensitive to the apparent limits or shortcomings that emerged with respect to the initial EC risk assessments; there is text and jurisprudence (EC-Hormones I, Appellate Body) that allows a margin of deference, or perhaps more accurately, sensitivity where divergent scientific views exist, and where progress or development in science itself leads to a different understanding of what the relevant risks to be assessed are, and the limits of existing techniques and methodologies for testing for those risks. While, as we argue, the Panel could have done better, this would have been a hard case to deploy such deference or sensitivity, because in effect it would have been deployed so as to uphold an outcome at odds with the judgments of the complainants' own regulatory bodies.

A second difficulty with the controversy underlying the EC-Biotech WTO dispute relates to the place of the SPS Agreement in judging food regulations that respond to public feelings that combine, somehow, concerns with health risks in the narrow sense with more ethical, religious, or spiritual misgivings. 'Man ist wass man isst', punned the nineteenth-century German philosopher Feurbach; the pun doesn't work in English, but the meaning is that 'we are what we eat'. The modern scientific, or more precisely secularist, worldview that arguably underpins the SPS agreement, and perhaps the entire WTO structure, implies a clear divide between the regulation of 'objective' risks, to health, the environment etc., which can be tested by science, and strictures that are faith-based, purely 'subjective', nonmaterial, or 'irrational', as would be understood to be the case with the dietary laws of particular religious communities. The proliferation of claims about foods that seem to concern 'physical' health but also in some measure spiritual concerns, such as claims that food is 'organic' or 'sustainable', evidence this trend. It appears as if people increasingly regard food choices as a matter of 'right living' - body 
and soul together - and they may see those choices not merely as individual lifestyle choices but ones with a collective or societal dimension. Obviously, to judge such choices by the standard meaning of 'science', would be to miss the point. In EC-Hormones I, the Appellate Body seemed to glimpse something of this difficulty and sought to alleviate it within the parameters of interpretation of the SPS text, by referring for instance to the possibility of a WTO Member relying on nonmainstream 'science' or by alluding to risk as not just risk to be tested in the laboratory but risk as seen in the real world where people live and die. Despite our criticisms of some of the details in the Panel's ruling on this point, arguably the EC-Biotech Panel made some strides in addressing this challenge in its findings concerning the relationship between SPS strictures and other WTO Agreements, in particular TBT. The Panel held that to the extent that a measure is motivated not simply by the kinds of objectives that define an SPS measure (including protection of life, health, and the environment) but by non-SPS concerns, even if it violates SPS through the lack of scientific foundation, the measure may still be WTO-legal; i.e., it may be sustainable as a measure justified by non-SPS purposes provided it is consistent with the other relevant WTO agreements, whether GATT or TBT (neither of which require a scientific foundation).

A third challenge raised by this case again, like the first one, has to do with public trust, but in this case it is a matter of trust in, or attitudes towards, multinational corporations. WTO dispute settlement provides no direct opportunity to confront the likes of Monsanto in the hearing room, yet the industry is very much behind the use of trade-law litigation to expand market access for GMOs. We do not wish in any way to take sides concerning the claims that have been made about the manner in which the industry may have put inordinate pressure on regulators, or hidden or suppressed relevant scientific evidence or studies that point to riskiness, or discouraged independent investigations of risk in this area by scientists not affiliated by the industry. One cannot in the abstract sort out 'conspiracy theory' type paranoia from documented cases of such behavior. However, there is in principle a problem of information asymmetry in this area in that the regulated entities, the industry, themselves possess much of the knowledge or information required to determine what risks need to be evaluated and concerning experience of those risks. Of course, the industry has certain incentives to disclose information, but there is also the obvious fact that it is in their interests to minimize public and regulatory perceptions of the riskiness of the products they are selling. The public imagination is filled with cases in other areas where information asymmetries played a crucial role in the failure to protect the public (tobacco being perhaps the most obvious). It is clearly quite difficult for a Panel to address this challenge, in part because it cannot summon industry witnesses, or impose any kind of duty of disclosure. While the Panel is placed by the text of the SPS in the position of doing a kind of regulatory review, and can seek scientific expertise and ask questions to scientists, it completely lacks the powers that one might expect of a domestic administrative tribunal or court, which may well have ways 
of holding not just the expert regulator to account, but the regulated industry itself.

A final challenge for WTO dispute settlement in this case is that the GMOs controversy between Europe and America, which appears to center narrowly on the acceptability of the choices that European authorities make with regard to the risks that are acceptable for their own citizens, nevertheless occurs in the shadow of a broader debate about the desirability, costs, and benefits more precisely, of GMOs as a strategy for development and food security in developing countries. This is a hotly contested matter within the developing world itself, and engages questions of global food, agricultural, and environmental policy. However carefully crafted and legally grounded the Panel's ruling might be, the way it came out was bound to be seen or used as legitimating the one position or the other in this rather polarized debate. Our criticisms of the Panel should not be seen as taking it to task for somehow improperly legitimating the pro-GMO side in that larger global-policy debate; nor as suggesting that we ourselves come out on the opposite, i.e., anti-GMO side. However, we think the Panel ran a greater risk of somehow appearing to silently or surreptitiously take sides in that debate (irrespective of whether justified from a strictly legal point of view) by excluding for use for interpretive purposes various international legal instruments that reflect, arguably, an attempt by a significant part of the world community to strike some kind of balance in the shadow of the broader debate, for instance the Biosafety Protocol, above all. The Panel also chose to not look at how international processes, such as the Codex Alimentarius process at the FAO, attempt to wrestle with these controversies affecting the interests of both the developing, as well as the developed world. It is to this issue of the Panel's shutting out of this broader universe of international legal and policy cooperation and coordination on these issues that we first now turn in our analysis of the ruling.

\section{The relationship between the WTO Agreement and other sources of international law ${ }^{2}$}

In its pleadings, the EC invoked the Cartagena Biosafety Protocol, ${ }^{3}$ to which both Canada and Argentina are signatories ${ }^{4}$ but not the United States, and the

2 This section is partly derived from Howse (2008).

3 The Cartagena Biosafety Protocol is a multilateral agreement that deals with international trade in Living Modified Organisms (LMOs). These include GMOs, but some of the obligations apply only to GMOs other than those intended for direct use as food or feed or for processing into food or feed. The Protocol is based on the Rio Biodiversity Convention to which the US is also not a party and its nonparticipation in the Rio Convention is an obstacle to the US adhering to the Cartagena Protocol. However, the US actively participated in the negotiations, and as part of the 'Miami Group' of (pro-GMO) countries, which also included Canada, shaped considerably the final outcome. On the negotiation of the Protocol and its provisions, see generally, Bail et al. (2002).

4 Neither has, however, ratified the Protocol so far. 
Precautionary Principle more generally in responding to the above legal arguments of the Complainants.

With respect to 'undue delay', 5 an expression never before given meaning in WTO case law, the EC pointed to the provisions of the Protocol that dealt with acceptable time frames for regulatory decisions. It noted that although the general time frame specified for decisions in the Protocol was 270 days, there was also a right under Article 8 to request additional information and accordingly extend the time frame for decisionmaking. ${ }^{6}$ Also, the EC noted Article 12(1) of the Protocol affirmed the right to review and change decisions on imports at any time in light of new scientific information on potential adverse effects on biodiversity, taking into account also risks to human health. In its defense against the claim of 'undue delay', the EC in its pleadings went on to argue that in each individual case delays could be explained precisely by factors such as the need for additional information or to reconsider or suspend the application in light of new scientific information or in order to consider the implications of that information.

The EC also invoked the Cartagena Protocol as evidence that GMOs were not 'like' their non-GMO analogues and therefore that the claim of a GATT nationaltreatment violation, based upon imported GMOs being treated worse than the non-GMO analogues, must fail ${ }^{7}$ (it should be emphasized that the EC measures did not treat imported GMOs less favorably than domestic GMOs, thus the only discrimination being alleged by Argentina and Canada was that between GMOs and non-GMO analogues).

Finally, with respect to the member-state 'safeguards', the EC argued that even though risk assessments had led the EC regulator to the conclusion that the products in question were adequately safe, other scientists had raised legitimate questions about the adequacy of the assessments as evaluations of all relevant risks, the quality of the science used in light of new scientific knowledge, and the methodologies in some instances. Based upon a precautionary approach to regulation, it was not unreasonable according to the EC for member states to provisionally ban the products in question in such circumstances in order to obtain a more adequate scientific judgment on their safety. Here the EC relied not only on 5.7 of SPS, but in the alternative, i.e. if the Panel found that 5.7 did not apply, the EC argued that the requirement that measures be based on scientific principles and sufficient scientific evidence (SPS 2.2) and on a risk assessment 5.1 should be interpreted in a precautionary manner, such that, where a risk assessment is considered inadequate or not based on state-of-the-art scientific knowledge, it is reasonable for a WTO Member to act with caution and ban or restrict the product

5 It is our intention to address the Panel's general consideration of 'undue delay' in a subsequent draft of this report.

6 'European Communities - Measures Affecting the Approval and Marketing of Biotech Products', First Written Submission by the European Communities, paras. 106-108.

7 Ibid. at para. 90 and para. 535. 
until more adequate science can be applied to the question. ${ }^{8}$ Here, in addition to the Precautionary Principle generally, a number of the provisions of the Biosafety Protocol (including the version of the Precautionary Principle incorporated in the Protocol) mentioned in the EC pleadings were argued to be clearly relevant, including the right to revise a regulatory decision at any time in light of new scientific knowledge or information $(12(1))$. As well, the EC noted in its pleadings a provision of Annex III of the Protocol, providing detailed guidelines on risk assessment, which stipulates that '[1]ack of scientific knowledge or scientific consensus should not necessarily be interpreted as indicating a particular level of risk, an absence of risk, or an acceptable risk'. This was taken to support the EC's position that member states need not act on the assumption that a product is safe when the scientific adequacy and comprehensiveness of the risk assessment had subsequently been credibly challenged.

The Panel responded to the EC by refusing to consider the Biosafety Protocol as well as the Precautionary Principle in general.

With respect to the Biosafety Protocol, the Panel interpreted the words 'applicable in relations between the parties' in Article 31(3)(c) of the Vienna Convention on the Law of Treaties (VCLT) as requiring that a rule of international law be binding between all the parties of the treaty being interpreted in order to be taken into account in the interpretation of that treaty. ${ }^{9}$ The Panel relied principally on three considerations in coming to this conclusion. The first was that generally in the VCLT the expression 'parties' is used to refer to parties to a treaty not parties to a dispute, and that the definition of 'party' in $2.1(\mathrm{~g})$ of the VCLT is ' a State which has consented to be bound by the treaty and for which the treaty is in force'. The second was the notion that:

[r] equiring that a treaty be interpreted in the light of other rules of international law which binds the States parties to the treaty ensures or enhances the consistency of the rules of international law applicable to these States and thus contributes to avoiding conflicts between the relevant rules. (para. 7.70)

Third, the Panel observed:

it is not apparent why a sovereign State would agree to a mandatory rule of treaty interpretation which could have as a consequence that the interpretation of a treaty to which that State is a party is affected by other rules of international law which that State has decided not to accept. (7.71)

\subsection{The interpretation of 'applicable in relations between the parties'}

Clearly, the textual argument of the Panel concerning the meaning of 'party' is not dispositive. There is no question that the 'parties' referred to in Article 31(3)(c)

8 See also the discussion below of the Panel's approach to Articles 5.1 and 5.7 of SPS. The Panel's failure to consider, contrary to the authoritative jurisprudence of the $\mathrm{AB}$ in EC-Hormones, the importance of precaution as a principle may be related to its erroneous approach to 5.1 and 5.7 and particularly the relationship between these two provisions.

9 EC-Biotech, paras. 7.67-7.71. 
VCLT have to be parties to the treaty being interpreted, whether or not the reference here is to all parties of the treaty or only to those of the parties of the treaty who are in the dispute. There is simply no inconsistency between the definition of 'party' in Article 2.1(g) VCLT and this latter reading of Article 31(3)(c). Moreover, in its textual analysis, the Panel failed to consider the language 'applicable in relations between'. If Article 31(3)(c) referred to the concept of the treaty having to be binding and in force for all the parties, why was this standard terminology, appearing as the Panel itself notes in the definitional parts of the VCLT, not used here? Why does the VCLT here instead use the expression 'applicable in relations between', which seems less to do with legal force but rather the appropriateness of the norm to the matters in dispute?

\subsection{The possibility of conflicting interpretations}

The Panel raises the possibility that by using a legal norm not applicable between all the parties to the treaty, although applicable to the particular parties to the dispute in question, the treaty interpreter would create a result that would lead to inconsistent interpretation, since another case might arise where the WTO issue is the same, but the parties to the dispute are not parties to the other treaty, and therefore the norms of that other treaty could not be applied in addressing the WTO issue. Here it should be emphasized, however, that Article 31(3)(c) VCLT only requires that 'other relevant rules of international law' be taken into account, and it supposes that such rules will merely be one element in a complex interpretative process.

Where there is considerable overlap between the collectivity of states adhering to various instruments that reflect a particular norm and the Membership of the WTO, the danger of conflicting interpretations in different disputes to which different WTO Members are parties is not going to be so great. In other instances, for example where a norm has very different formulations in different regional or plurilateral agreements, the possibility of conflicting or divergent interpretations of WTO law, depending on who are the parties to a given dispute, may be a real risk, and applying the norm in WTO interpretation could exacerbate the fragmentation of trade law already occurring because of the proliferation of regional trading arrangements.

Instead of wholesale rejection of most other relevant international law in WTO interpretation - the implication of the Panel's ruling that all WTO Members must be parties to the other instrument - the legitimate underlying concerns about importing other legal norms for interpretative purposes might be addressed by selective caution and sensitivity in the use of non-WTO legal material in this way, perhaps based on the following admittedly imprecise guidelines:

- an international norm from one regime that is being applied in interpretation in another regime should be appropriately cross-contextual. An example of inappropriate cross-contextuality would be the use of the principle of precaution to 
interpret the norms of self-defense in the UN Charter to permit preemptive use of force. This is inappropriate, in part, because the context in which the precautionary principle emerged was such that no discussion or reflection on the values and interests relating to the use of force occurred.

- the values of democracy and self-determination require that a treaty interpreter be attentive, in cases where there is not formal state consent to be bound, to the risk of giving normative effects to an international-law rule that the people of a particular state, party to the dispute, have had no opportunity to shape or influence.

- but at the same time, such considerations may be outweighed to the extent that the norms to be applied in interpretation reflect recognized universal values (human rights and humanitarian principles for example) that are expressed in custom or ius cogens (preemptory norms of international law) even if the specific norm itself does not have the status of custom or ius cogens.

- the openness and inclusiveness of the process by which the norm was generated should be taken into consideration.

\subsection{Should WTO Members be bound by agreements they are not members of?}

As for the Panel's third consideration - that it is 'not apparent' why a WTO Member should be bound by agreements they are not members of - it should first of all be noted that one does not need to go to case law to find this notion incorporated into WTO law, it can even be found in the text itself; for instance Art. 3.1 SPS requires that:

Members shall base their sanitary or phytosanitary measures on international standards, guidelines or recommendations, where they exist, except as otherwise provided for in this Agreement, and in particular in paragraph 3.

Also, Panels and the Appellate Body $(\mathrm{AB})$ have in their interpretations of both the SPS and TBT Agreements given considerable legal force to 'international standards' - norms created by bodies that are often largely private in nature, where the intention is to create voluntary standards, where not all WTO Members are participants, and where the decisionmaking may deviate from consensus. ${ }^{10}$

In dealing with the Precautionary Principle, the Panel simply asserted that despite developments in international law since the $\mathrm{AB}$ EC-Hormones ruling, it remained unclear whether the Precautionary Principle was a rule of customary international law. The Panel then suggested that as with the AB in EC-Hormones,

10 See Appellate Body Report, European Communities - Trade Description of Sardines (Sardines), WT/DS231/AB/R, adopted 23 October 2002, where the obligation in 2.4 of the TBT Agreement to use 'international standards' as a basis for domestic mandatory regulations was held to include standards that were made by international-standards bodies deviating from consensus decisionmaking. In any case, the TBT Agreement requires only that such bodies be open to the relevant standardization entities of all WTO Members and does not require that all Members participate in the bodies in question for their standards to have legal force pursuant to 2.4 . 
it did not need to decide the question in order to dispose of the legal claims before it (para. 7.89).

Of course, as we saw in EC-Hormones, the AB did not find it necessary to decide whether the Precautionary Principle was a general principle or custom, because the AB felt that it could have weight in the interpretation of SPS without being either. This raises the issue of how the Panel in EC-Biotech was able to avoid the obvious fact that the $\mathrm{AB}$ jurisprudence had made extensive use of international law, including international environmental law, without invoking in particular Article 31(3)(c) VCLT. The highly restrictive reading of Article 31(3)(c) by the Panel would seem in tension with the $A B$ practice, informed apparently by the notion that there is a broader basis in canons of treaty interpretation for the use of international law of which Article $31(3)$ (c) is simply one particular nonexhaustive elaboration.

The Panel's answer comes in the attempt to squeeze this broader use of international law into the notion that a treaty interpreter can use international law like a dictionary, as a source of 'ordinary meaning' (para. 7.92). Why then did the Panel simply not proceed to treat the international legal materials invoked by the $\mathrm{EC}$ in this way?

First of all, the Panel suggests that the EC never explained the relevance of these sources to the interpretation of the WTO treaty provisions in dispute. However, as discussed above, the relevance on several matters is very evident from the initial pleadings of the EC. Secondly, and in some tension with the questionable statement just mentioned, the Panel stated:

We have carefully considered the provisions referred to by the European Communities. Ultimately, however, we did not find it necessary or appropriate to rely on those particular provisions in interpreting the WTO agreement at issue in this dispute. (7.95)

This is the sum total of explanation given by the Panel in rejecting the provisions of the Biosafety Protocol, a detailed code on risk assessment and regulatory control of GMOs accepted by 188 states, as of any relevance to resolving the dispute. Of course, a 'right' interpretation of the WTO law at issue in the dispute might have produced the same reading of the WTO text even if appropriate weight were given to the international legal sources in question. But since the EC had invoked those sources, the Panel was arguably under a duty to explain why this was the case, i.e. either that the norms led to the same interpretation as would otherwise be correct (i.e., they were not 'necessary') or why it was not 'appropriate' to give them weight.

However, we wish to be very clear that use of non-WTO norms as interpretative material in a reading that is always guided by the WTO text itself is quite a different matter than applying these norms themselves as binding law, in such a way as to trump or add to existing rights or obligations of the Membership. Only where such norms have achieved the status of ius cogens, or an inter se amendment of 
WTO rights and obligations as between particular WTO Members, or are explicitly incorporated into WTO law (the case for certain WIPO conventions on intellectual property in TRIPs), ${ }^{11}$ or where they are in conflict with WTO rules but in a treaty later in time on the same subject matter, or in conflict with the UN Charter, would such applications of non-WTO law be appropriate. However, these issues, which are mostly issues that concern conflict of treaties - dealt with in extenso by Pauwelyn (2003) - were not present in the EC-Biotech case. Unlike what was argued with respect to the precautionary principle in EC-Hormones I, the EC's memorial in EC-Biotech makes it clear that the EC was invoking the nonWTO norms in question only as part of the relevant interpretative universe, not as binding or superior law.

In fact, the preamble to the Biosafety Protocol itself indicates that it is not intended to prevail over or alter the actual legal rights and obligations of the parties in other international agreements (i.e., as opposed to assisting in the interpretation of what those rights and obligations mean).

Emphasizing that this Protocol shall not be interpreted as implying a change in the rights and obligations of a Party under any existing international agreements,

Understanding that the above recital is not intended to subordinate this Protocol to other international agreements,

In this respect, we must bear in mind the full text of Article 3.2 of the DSU: on the one hand the dispute settlement organs must not add to or diminish the rights or obligations in the covered agreements; but on the other hand, these rights and obligations are themselves according to 3.2 not defined in isolation, but rather as interpreted in accordance with the rules of interpretation in customary international law (understood to be reflected in the VCLT). Thus, it follows that using the Biosafety Protocol to make sense of provisions in the SPS Agreement could not, by the very terms of 3.2 when read as a whole, add to or diminish the rights and/or obligations in SPS provided that such interpretation is in accord with approaches to treaty interpretation in customary international law.

11 The fact that the Biosafety Protocol has not been incorporated through explicit reference in WTO law is thus a consideration militating against the application of its norms as binding on WTO Members; but, again, we emphasize that what the EC was requesting of the Panel was merely to include the relevant provisions of the Protocol as part of the interpretative material for applying the WTO norms themselves. If parties to a treaty were expected to include an explicit reference to a rule of international law in order for it to be relevant to interpreting that treaty, then VCLT Article 31(3)(c) would be largely superfluous. By contrast, Article 31(3)(c) when correctly understood, as by the ILC Working Group on Fragmentation and the ICJ in Oil Platforms (opinion of the Court) establishes a default rule that other relevant rules of international law must be taken into account in the interpretation of a treaty. Given this default rule, it would be for the parties of a treaty to explicitly contract that a particular legal rule or regime not be taken into account in the interpretation of the treaty. 


\subsection{AB jurisprudence on the relationship between the WTO Agreement and other international agreements}

We will end our discussion of the relationship between the WTO Agreement and other international agreements by briefly discussing $\mathrm{AB}$ jurisprudence on this issue. It is useful to first make the contrast with the $\mathrm{AB}$ in US-Shrimp in its analysis of the meaning of 'exhaustible natural resources'; in that case, as we observed, the $\mathrm{AB}$ gave pride of place to international environmental law in its interpretative exercise even though the interpretation it offered could have been grounded primarily or indeed entirely upon GATT precedent and its reading of the negotiating history. Conversely, in EC-Biotech, even assuming there were other persuasive considerations to support its interpretation, the Panel could have at least engaged with the norms of the Biosafety Protocol, explaining the consistency of its interpretation with them or why in particular cases they were not appropriate to use in understanding provisions of the WTO Agreements. The difference in approach may in fact come down to the AB's interest in enfranchising environmental interests and constituencies in WTO dispute settlement, and the Panel's concern (possibly reflecting the insider perspective of the WTO Secretariat, which has a large influence in the drafting of Panel decisions) to enfranchise those interests and constituencies as little as possible.

Taken on its own, EC-Biotech could be seen as reflecting the Panel's failure to understand the approach of the $\mathrm{AB}$ to the use of non-WTO international law in interpreting the covered agreements. The EC did not appeal the EC-Biotech Panel ruling so the $\mathrm{AB}$ had no opportunity to comment on it. The $\mathrm{AB}$ ruling in Mexico-Soft Drinks, however, raises the possibility that the $\mathrm{AB}$ itself has moved towards a more constrained role for non-WTO international law in WTO litigation. In Mexico-Soft Drinks, the AB had to adjudicate Mexico's defense that its measure was 'necessary' to secure compliance with laws and regulations, within the meaning of GATT XX(d). The essence of Mexico's argument was that the US had violated the NAFTA in its application of antidumping law to Mexico and had obstructed the dispute settlement process available to Mexico under NAFTA to enforce its rights. While rejecting Mexico's invocation of Article XX(d) on other grounds (namely, that the phrase 'laws and regulations' in XX(d) does not extend to international legal norms that have not been made effective in a Member's municipal law), among the findings of the AB was that the WTO dispute settlement organs lack jurisdiction to make determinations with respect to compliance with international legal norms outside the covered agreements, in this instance, the NAFTA (para. 56). The AB appeared to be saying that it could not entertain Mexico's defense because doing so would require it to determine rights and obligations under non-WTO law. This seems to get the legal question backward. If Mexico's interpretation of Article XX(d) is correct, then the AB has jurisdiction to make a determination as to whether the US has violated the NAFTA to the extent that this is necessary in order to apply $\mathrm{XX}(\mathrm{d})$ properly interpreted. It is obvious 
that the $A B$ would not have jurisdiction to make a determination under the NAFTA except to the extent it is interpreting and applying WTO law, but this does not in itself preclude application of WTO law in that way. There is no reason, conversely, to reject Mexico's interpretation of Article XX(d) on the assumption that WTO provisions should be read as not intended to involve determinations under other legal orders. Plainly, this was contemplated by Members when they incorporated large parts of the great intellectual-property conventions into TRIPs, or, for instance, when they made compliance with OECD export-credit rules relevant to the determination of whether a subsidy is prohibited under the Agreement on Subsidies and Countervailing Measures (SCM Agreement). It is difficult to square the approach of the $\mathrm{AB}$ in Mexico-Soft Drinks with its remarks in EC-Bananas, where the $\mathrm{AB}$ had no doubt that to the extent required to interpret and apply the Lome Waiver, the Panel and the AB could determine what was 'required' under the Lome Convention (paras. 167-168). It is true that one may distinguish instances where the non-WTO law is explicitly or implicitly referred to in a WTO instrument from those where it is not. However, if Mexico was correct in the view that 'laws or regulations' in Article XX(d) included international law, then Article XX(d) itself would contain an explicit reference to non-WTO international law. Of course, the $A B$ rejected that view, holding instead that only to the extent incorporated or implemented in domestic law, did international law fall within Article XX(d). So perhaps all the AB was saying in Mexico-Soft Drinks was that it had no jurisdiction to make a determination of rights and obligations under non-WTO legal instruments apart from the case where there is some reference, implicit or explicit, to non-WTO law in the relevant WTO instruments. This would make some sense of the AB's holding, since it would flow from the AB's reading of Article $\mathrm{XX}(\mathrm{d})$ rather than being some spurious invented constraint on the use of non-WTO law - flowing from the notion of the WTO as a 'self-contained regime' for example (a view long rejected by the $\mathrm{AB}$ ). In the case of US-Shrimp, the reference to 'sustainable development' was sufficient for the AB to bring into its interpretation the international law of biodiversity. In EC-Bananas, it was enough that there was a reference to the requirements of the Lome Convention in the relevant WTO instrument, the Lome Waiver. Similarly, in Turkey-Textiles, Article XXIV of the GATT, as interpreted by the AB, requires that the WTO dispute settlement organs examine what is required for the existence of a customs union or free-trade area, which implies determinations concerning the rights and obligations under the instrument establishing the customs union or free-trade area.

The facts in Mexico-Soft Drinks raised the issue of possible determinations based on similar or identical legal texts in more than one forum (in this case NAFTA, as well as the WTO) and also the issue of these two fora making a decision in essentially the same dispute. These choice-of-forum issues were not addressed head on by the $\mathrm{AB}$; rather the $\mathrm{AB}$ instead finessed or conflated them with the question of whether, in the course of interpreting a provision of a WTO treaty 
(in this case, GATT Article $\mathrm{XX}(\mathrm{d})$ ) it could make findings, en passant, as it were, about a WTO Member's compliance with a non-WTO legal norm.

As a matter of general international law, the remarks of the International Court of Justice (ICJ) in the recently decided case of Bosnia-Herzegovina v. Serbia suggest that there is no intrinsic restraint on the possibility of the rights and obligations under a single international instrument being the subject of determination in more than one forum, provided each forum has a jurisdictional basis for adjudicating. In that case, among Serbia's arguments on jurisdiction was that since state responsibility for genocide could only occur through attribution to the state of the acts of individuals that are criminal under the law of genocide, the ICJ could not adjudicate Bosnia-Herzegovina's claim except to the extent that there were prior criminal convictions in respect of the acts alleged. The ICJ held:

The different procedures followed by, and powers available to, this Court and to the courts and tribunals trying persons for criminal offences, do not themselves indicate that there is a legal bar to the Court itself finding that genocide or the other acts enumerated in Article III have been committed. (181)

If one were to apply this reasoning to the situation in Mexico-Soft Drinks, it would imply that the WTO dispute settlement organs, fulfilling a different role than that of a NAFTA Panel, could nevertheless make a determination without the necessity of a prior ruling in NAFTA. Of course, were WTO dispute settlement organs to make a ruling prior to that of a NAFTA Panel then the question of res judicata would arise. Perhaps this is the AB's concern, namely that it does not view a WTO adjudicator as having the jurisdiction to make a determination of rights and obligations under NAFTA that is binding on them as NAFTA parties. However, and again the remarks of the ICJ in Bosnia-Herzegovina v. Serbia are apposite, it would be up to the NAFTA tribunal itself to determine what weight to give in a NAFTA dispute to any prior determinations of the WTO dispute settlement organs.

\section{GATT Article III:4 (national treatment)}

While exercising judicial economy with respect to Canada's claim of a GATT Article III :4 national-treatment violation (because of its considerable overlap with the 'undue delay' claim under SPS), the Panel went on to address Argentina's claim that the:

measures at issue have modified the conditions of competition in the EC market to the detriment of imported biotech products. Argentina notes in this regard that as a result of the alleged suspension of consideration of, or the failure to consider, the relevant eight applications the biotech products which are the subject of these applications were not approved.

As the Panel noted, Argentina's claim was premised on the notion that 'like' nonbiotech products could continue to be marketed in the EC without bearing the burden of such approvals and the resultant delays (Panel Report, 7.2512). 
The Panel's analysis of Argentina's claim was as follows:

7.2511 We initially focus our analysis on the 'no less favourable treatment' obligation contained in Article III:4, rather than on the 'like products' element. We recall in this connection that the Appellate Body in EC-Asbestos and Dominican Republic-Import and Sale of Cigarettes made statements in relation to the meaning of the phrase 'no less favourable treatment' in Article III:4. We find these statements to be relevant to the type of measures challenged by Argentina under Article III:4.

7.2512 Argentina contends that, as a result of the alleged suspension of consideration of, or the failure to consider, the relevant eight applications, the European Communities has accorded 'less favourable treatment' to the biotech products which are the subject of the eight applications than to like non-biotech products. More particularly, Argentina considers that the measures at issue have modified the conditions of competition in the EC market to the detriment of imported biotech products. Argentina notes in this regard that as a result of the alleged suspension of consideration of, or the failure to consider, the relevant eight applications the biotech products which are the subject of these applications were not approved.

7.2513 In considering Argentina's contention, the first thing to be observed is that Argentina has not provided specific factual information about the treatment accorded by the European Communities to the non-biotech products which Argentina considers to be like the biotech products at issue. It appears to be Argentina's contention, however, that these non-biotech products may be marketed in the European Communities, whereas the relevant biotech products may not be marketed.

7.2514 At any rate, even if it were the case that, as a result of the measures challenged by Argentina, the relevant imported biotech products cannot be marketed, while corresponding domestic non-biotech products can be marketed, in accordance with the aforementioned statements by the Appellate Body this would not be sufficient, in and of itself, to raise a presumption that the European Communities accorded less favourable treatment to the group of like imported products than to the group of like domestic products. We note that Argentina does not assert that domestic biotech products have not been less favourably treated in the same way as imported biotech products, or that the like domestic non-biotech varieties have been more favourably treated than the like imported non-biotech varieties. In other words, Argentina is not alleging that the treatment of products has differed depending on their origin. In these circumstances, it is not self-evident that the alleged less favourable treatment of imported biotech products is explained by the foreign origin of these products rather than, for instance, a perceived difference between biotech products and non-biotech products in terms of their safety, etc. In our view, Argentina has not adduced argument and evidence sufficient to raise a presumption that the alleged less favourable treatment is explained by the foreign origin of the relevant biotech products. 


\subsection{Commentary}

As the $\mathrm{AB}$ has consistently stressed, the determination of whether a measure violates Article III:4 entails a two-step test. The first step is to ascertain whether the imported products are 'like' the domestic products in relation to which the complainant is claiming that the imports are being treated less favorably. The second step, in turn, is to ascertain whether the measure in fact causes less favorable treatment of the 'group' of like imported products versus the group of domestic products (see for instance EC-Asbestos, para. 100). ${ }^{12}$

In EC-Biotech, the Panel made the unprecedented move of considering whether the claimant had made a prima facie case of less favorable treatment, without first ascertaining whether they had made a prima facie case that there was a like group of domestic products against which the treatment of the imports could be properly compared. This approach is, to say the least, very difficult to understand. The standard of 'less favourable treatment', central to national treatment, is inherently a comparative or relative one, and we find it implausible that such a standard could be applied properly, even in assessing the existence of a prima facie case, in the absence of a comparator..$^{13}$ It is arguable that, in fact, to the extent coherent, the Panel's analysis 'of treatment no less favourable' assumes that what is being compared is the treatment of 'imported biotech products' and 'domestic nonbiotech products'. On one reading, then, the Panel was making a surreptitious or covert statement that such products can be considered sufficiently like prima facie (i.e. based on the criteria for likeness employed in the jurisprudential acquis, Japan-Alcohol, etc.). Yet a full analysis of 'likeness' based on the approach used in EC-Asbestos, which adapts the Japan-Alcohol methodology to Article III:4, would seek to determine what a hypothetical 'reasonable' consumer would infer about the risks of the two types of products. The outcome of such an exercise is highly unclear. Moreover, given the significance of physical characteristics in EC-Asbestos, including any differential health risks that might follow from different physical characteristics, the Panel would have had to consider the implications of the physical differences between GMO and non-GMO products: conceptually, differences that flow from genetic dissimilarity are 'physical'.

But there is an alternative way of understanding the logic of the Panel: that it is attempting to push the jurisprudence in a different direction, namely towards in effect, a full-scale return to the 'aims and effects' approach to Article III:4 that was characteristic of certain Panel decisions under the GATT in the early 1990s. Under this approach, a determination of whether there is a violation of Article III:4 is, in the first instance, a matter of ascertaining whether the measure evidences an intent to discriminate on the basis of the national origin of the products. This approach was explicitly and wholly rejected by the AB Japan-Alcoholic Beverages II in favor

12 The significance of making a comparison between the two 'groups' of products is explored in detail in Howse and Türk (2006).

13 See Horn and Weiler (2003). 
of the 'objective' market-competition approach, as embodied in the application of the criteria in the Border Tax Adjustment Working Party for the determination of likeness; at least, in the first step of determinations of 'likeness' regulatory purpose, either actual legislative intent, or objective purpose in terms of the design and structure of the measure should play no role in the analysis. However, as Regan (2006), Trebilcock and Howse (2005), Howse and Türk (2006), and others have noted, in cases subsequent to Japan-Alcoholic Beverages II, the AB has qualified the rather sweeping rejection of 'aims and effects' in Japan-Alcoholic Beverages $I I$, bringing considerations of regulatory purpose in terms of national-origin discrimination into the consideration of whether there is 'protection' in the sense of the second sentence of Article III:2 (Chile-Alcohol), or into the analysis of 'less favourable treatment' (Dominican Republic-Cigarettes). However, in none of these cases, has the $A B$ ever suggested that one could dispense with the first step of determining likeness based on 'objective' criteria.

By contrast, what the Panel in EC-Biotech appears to be doing is introducing a requirement of prima facie evidence of discrimination on the basis of national origin as a condition precedent for even considering a claim of a violation of national treatment. Thus, the following language of the Panel:

even if it were the case that, as a result of the measures challenged by Argentina, the relevant imported biotech products cannot be marketed, while corresponding domestic nonbiotech products can be marketed, in accordance with the aforementioned statements by the Appellate Body this would not be sufficient, in and of itself, to raise a presumption that the European Communities accorded less favourable treatment to the group of like imported products than to the group of like domestic products. We note that Argentina does not assert that domestic biotech products have not been less favourably treated in the same way as imported biotech products, or that the like domestic non-biotech varieties have been more favourably treated than the like imported nonbiotech varieties. In other words, Argentina is not alleging that the treatment of products has differed depending on their origin. In these circumstances, it is not self-evident that the alleged less favourable treatment of imported biotech products is explained by the foreign origin of these products rather than, for instance, a perceived difference between biotech products and non-biotech products in terms of their safety, etc. ... (7.2514, emphasis added)

Here, the Panel seems to have adopted the core logic of advocates of an 'aims and effects' approach to Article III: Article III should only discipline protective discrimination attributable to national origin and should not affect regulations attributable to nonprotectionist public-policy purposes.

The choice between a 'market competition' approach to Article III, which leaves a significant role for Article XX of the GATT in the justification of measures that affect competition but nevertheless have legitimate public-policy purposes, and an 'aims and effects' approach supported by commentators such as Howse and Regan (2000), among others, is often argued to engage crucial 'constitutional' (as 
John Jackson would put it) or systemic legitimacy questions about the relationship of WTO law to regulatory democracy. Others again, such as Horn and Mavroidis (2004), suggest that likeness should be determined 'in the market place', and with increased emphasis being put on the 'so as to afford protection' criterion, which in their view should be read as referring to the intent behind domestic regulations.

It is true that one sees in EC-Asbestos and Dominican Republic-Cigarettes some 'slippage' back towards elements of 'aims and effects'. At the same time, we find it extraordinary, regardless of the particular solution that each of us has advocated, that the Panel should make such a large jurisprudential step without in any way engaging with these larger issues, or the rationales for the AB's rejection of aims and effects in the first place, in early rulings such as Japan-Alcohol II and EC-Bananas.

\section{The scope of application of the SPS Agreement and the relationship between SPS and TBT measures}

Under the law of the WTO, the legal constraints that are imposed on a domestic regulatory measure, as well as the scope for defending the measure (e.g., Article XX of the GATT) may well vary depending on the measure's purposes. However, in the real world of democratic regulatory politics, a regulation is rarely enacted to serve only one purpose. How, then, to address within the WTO legal framework, regulations that have multiple (nonprotectionist) purposes? Both the SPS Agreement in general and the facts of the GMOs dispute in particular pose this question in a pointed manner. First of all, under SPS the very scope of an SPS measure is defined in terms of the measure's purposes. If a measure does not correspond to any of those purposes, ${ }^{14}$ then the specific additional disciplines (i.e. additional to the GATT) of SPS do not apply to it. The question then becomes whether the measure falls within the scope of the TBT Agreement. If not, then GATT Article III:4, which applies generally to domestic 'laws, regulations, and requirements' will likely be the applicable law, along with any defenses available for example under Article XX. It should be noted that the disciplines of SPS and TBT are not cumulative, so that if a measure is considered an SPS measure, the disciplines of TBT do not apply. Under TBT, WTO Members are not required to base their measures on scientific principles or scientific risk assessment. Only to the

14 These are stated in Annex A(1) of the SPS Agreement: '(a) to protect animal or plant life or health within the territory of the Member from risks arising from the entry, establishment or spread of pests, diseases, disease-carrying organisms or disease-causing organisms;

(b) to protect human or animal life or health within the territory of the Member from risks arising from additives, contaminants, toxins or disease-causing organisms in foods, beverages or feedstuffs;

(c) to protect human life or health within the territory of the Member from risks arising from diseases carried by animals, plants or products thereof, or from the entry, establishment or spread of pests; or (d) to prevent or limit other damage within the territory of the Member from the entry, establishment or spread of pests.' 
extent that a measure serves the purposes articulated in Annex A(1) of SPS, must it be required to be justified scientifically. Thus, in the case of GMOs, if a WTO Member were to enact a ban or some less stringent measure for other purposes, such as to address ethical, religious, or lifestyle concerns about GMOs, there is no question that it could enact such a measure without the requirement of scientific justification. Indeed, it would be incoherent to require scientific evidence in such a case, because the measure is motivated by considerations that are not amenable to scientific analysis. The question becomes whether the right of a WTO Member to enact such a measure without scientific justification is qualified or attenuated where the measure is also enacted to serve the purposes in SPS. If the measure fails the SPS requirements of scientific justification, does it become impermissible per se, despite the fact that had it been enacted purely for non-SPS purposes it would not be WTO-illegal? Here is the Panel's answer to this important question ${ }^{15}$

7.151 The European Communities argues that the SPS Agreement has a limited scope of application and that the scope is defined by reference to the objective, or purpose, of the measure at issue, that is the reasons justifying the measure. The European Communities considers that if a WTO Member acts for two different reasons, one of which falls within the scope of the SPS Agreement, and the other of which does not, there are in effect two different measures for WTO purposes. According to the European Communities, this is so even if the two different objectives are sought to be achieved by a measure reflected in a single document. The measure (or part thereof) taken for any of the reasons enumerated in the SPS Agreement falls within the scope of that Agreement. The measure (or part thereof) taken for other reasons falls outside the scope of the SPS Agreement.

$\cdots$

7.161 Argentina argues that the European Communities admits that the measures at issue in this dispute which affect the approval and marketing of biotech products are partially covered by the SPS Agreement. According to Argentina, the SPS Agreement is the agreement to be applied, since it refers to the protection against certain risks and not against certain products. Argentina further submits that in accordance with Article 1.5 of the TBT Agreement the SPS Agreement and the TBT Agreement are mutually exclusive. Finally, Argentina contends that, by definition, a measure cannot be a series of measures.

7.162 The Panel considers that the issue raised by the European Communities is best analysed using a hypothetical example. Thus, assume that a Member imposes two identical requirements with regard to a particular product, and that each of the two requirements is laid down in a separate law. The law containing the first requirement states that that requirement is applied for one of the purposes enumerated in Annex A(1) of the SPS Agreement. The law containing the second requirement states that the second requirement is applied exclusively for a different purpose, one which is not covered by Annex $\mathrm{A}(1)$. Clearly, the first

15 The footnotes appearing in this quotation are original, but with new numbering. 
requirement would qualify as an SPS measure, as it meets the form (law), nature (requirement) and purpose (one of the enumerated purposes) elements of the definition of the term 'SPS measure' as provided in Annex A(1). Equally clearly, the second requirement would not qualify as an SPS measure. While it would meet the form (law) and nature (requirement) elements of the definition of an SPS measure, it would not satisfy the purpose element, as it is not applied for one of the purposes enumerated in Annex A(1). Needless to say, however, the second requirement would also constitute a measure for WTO purposes. For simplicity, we refer to it here as the 'non-SPS measure'.

7.163 Now assume that the Member concerned decides to consolidate the two separate laws which contain the identical requirements into one single law. Since the two requirements in question are identical, the relevant requirement is included only once in the consolidated law. As the two independent purposes of the requirement in question remain as valid as before, the consolidated law specifies that the requirement is applied for both purposes. The issue now arises whether the requirement in the consolidated law (hereafter 'the requirement at issue') constitutes an SPS measure or a non-SPS measure, or both.

7.165 In our assessment, the better and more appropriate view is that of the European Communities. Hence, we consider that to the extent the requirement in the consolidated law is applied for one of the purposes enumerated in Annex $\mathrm{A}(1)$, it may be properly viewed as a measure which falls to be assessed under the SPS Agreement; to the extent it is applied for a purpose which is not covered by Annex A(1), it may be viewed as a separate measure which falls to be assessed under a WTO agreement other than the SPS Agreement. It is important to stress, however, that our view is premised on the circumstance that the requirement at issue could be split up into two separate requirements which would be identical to the requirement at issue, and which would have an autonomous raison d'être, i.e., a different purpose which would provide an independent basis for imposing the requirement.

7.166 We recognize that, formally, the requirement at issue constitutes one single requirement. However, neither the WTO Agreement nor WTO jurisprudence establishes that a requirement meeting the condition referred to in the previous paragraph may not be deemed to embody two, if not more, distinct measures which fall to be assessed under different WTO agreements. We note that Annex A(1) of the SPS Agreement, which defines the term 'SPS measure', refers to '[a]ny measure' and to 'requirements'. But these references do not imply that a requirement cannot be considered to embody an SPS measure as well as a non-SPS measure.

7.167 We note the United States' and Argentina's argument that Article 1.5 of the TBT Agreement supports a different conclusion. To recall, Article 1.5 states that the provisions of the TBT Agreement 'do not apply' to SPS measures as defined in Annex A(1) of the SPS Agreement. The operation of Article 1.5 is best illustrated 
by reference to the specific case of our hypothetical requirement contained in the consolidated law. To that end, we assume that the consolidated law qualifies as a technical regulation within the meaning of Annex 1(1) of the TBT Agreement. ${ }^{16}$ We have stated above that to the extent the requirement in the consolidated law is applied for one of the purposes enumerated in Annex A(1) of the SPS Agreement, it can be viewed as an SPS measure. As such, it falls to be assessed under the SPS Agreement, provided the measure may affect international trade. ${ }^{17}$ Article 1.5 makes clear that to the extent the requirement at issue qualifies as an SPS measure, the provisions of the TBT Agreement would 'not apply', even though the requirement at issue is contained in a law which meets the definition of a technical regulation. We have also said that to the extent the requirement at issue is applied for a purpose not covered by Annex A(1) of the SPS Agreement, it can be viewed as embodying a non-SPS measure. By its terms, Article 1.5 is not applicable to non-SPS measures. However, given that the requirement is assumed to be part of a technical regulation, it falls to be assessed under the TBT Agreement, to the extent it embodies a non-SPS measure. ${ }^{18}$ As the foregoing considerations demonstrate, our view that a requirement may in certain cases incorporate more than one measure is consistent with, and gives meaning and effect to, the provisions of Article 1.5. Therefore, we do not agree that Article 1.5 compels a different view.

7.168 In addition to the foregoing considerations, there is another consideration which we think militates against treating the requirement at issue as constituting only an SPS measure. To see this, it should first of all be recalled that, as a general matter, Members impose requirements because they consider it necessary to do so. ${ }^{19}$ If they do deem it necessary to impose a particular requirement, it is only logical that they also seek to minimize the risk of a successful legal challenge, whether before a domestic court or at the WTO. In the case of our hypothetical example, the Member concerned would face the risk - for instance, due to uncertainties as to the correct interpretation or application of relevant WTO provisions - that a WTO panel would find the requirement at issue to be WTOinconsistent as an SPS measure but WTO-consistent as a non-SPS measure, or vice versa, or that a panel would find the requirement to be WTO-inconsistent either as an SPS or as a non-SPS measure.

16 'Annex 1(1) defines a technical regulation as a "[d]ocument which lays down product characteristics or their related processes and production methods, including the applicable administrative provisions, with which compliance is necessary". Annex 1(1) further specifies that a technical regulation "may also include or deal exclusively with terminology, symbols, packaging, marking or labelling requirements as they apply to a product, process or production method".'

17 'Articles 1.1 and 1.2 of the SPS Agreement make clear that the SPS Agreement applies to all measures which (i) meet the definition of an SPS measure provided in Annex A(1) and (ii) may affect international trade.'

18 'We note that according to Article 1.4 of the SPS Agreement, "[n]othing in this Agreement shall affect the rights of Members under the [TBT Agreement] with respect to measures not within the scope of this Agreement",'

19 'Article 2.1 of the SPS Agreement provides that "Members have the right to take [SPS] measures necessary for the protection of human, animal or plant life or health, provided that such measures are not inconsistent with the provisions of [the SPS Agreement]".' 
7.169 If the view were taken that the requirement at issue would constitute an SPS measure only, the Member concerned would have to defend that requirement as an SPS measure. In view of the possibility that the requirement at issue might withstand scrutiny by a WTO panel as a non-SPS measure, but not as an SPS measure, it is reasonable to assume, however, that, ex abundanti cautela, the Member concerned would not want to forgo the opportunity of defending the requirement at issue also as a non-SPS measure. The Member concerned could prevent this by enacting the requirement at issue twice, either in different laws with a statement of the appropriate purpose or in the same law as separate provisions with a statement of their different purpose. However, a Member might face substantial difficulties in convincing its legislators of the need for enacting the same requirement twice, whether it be in different laws or as separate provisions in the same law. Moreover, pursuing this option might run counter to many Members' basic legislative objectives and requirements. It is axiomatic that the primary objective of legislation is to communicate directives to those affected by it in a manner that is clear, easily understandable and reduces uncertainties. By enacting the same requirement twice, in different laws or as separate provisions in the same law, a Member would arguably reduce clarity and create a potential for confusion and uncertainty among those affected by the law. Also, if the same requirement were enacted twice in different laws, the result would be a more fragmented domestic legal order. [emphasis in original]

\subsection{Commentary}

In general, we agree with the Panel's analysis and the reasoning behind it, which displays a sound understanding of the real-world complexities and subtleties of regulation and administrative law. Nevertheless, by using a simplified hypothetical, which presumes a single identical regulation, all of the features of which, can be understood as serving both the SPS and non-SPS purposes of the measure, the Panel ruling may fail to come to grips adequately with the challenges posed by regulations with multiple purposes.

The Panel's argument is unproblematic as long as we are concerned with a 'binary' measure, a measure that is either 'off' or 'on', such as when the choice is between a complete sales ban or no restriction at all. It could then be the case that either of the SPS and the non-SPS motives suffices in order to make the government ban the product (to choose 'on'). Or, slightly more generally, the argument is fine if the measure can in principle take a range of values, but the government with either motive would choose a corner solution in this range. For instance, one may allow any volume between the laissez-faire solution, and a complete prohibition (a zero volume), but the government would choose the complete ban in either case. But policy decisions typically involve trade-offs between various interests, and the optimal solution is often not to choose a corner solution. For instance, dangerous materials may be banned for most uses, but not for certain very special purposes. In such cases it will typically be the case that the optimal decision will depend on 
the 'number of policy rationales' for regulating the product. For instance, if a measure is invoked both for SPS and non-SPS reasons, it may be more stringent than if it is only invoked for non-SPS reasons. In such cases, the Panel's argument becomes more problematic.

More generally, if we consider the 'measure' to be an integrated regulatory framework that addresses multiple purposes in relation to GMOs, parts of the regulatory framework might only be explicable in terms of the SPS purposes of the measure. If the measure is found to violate SPS to the extent it is an SPS measure, but the WTO Member in question wants to continue to regulate to serve the nonSPS purposes in question, must it now withdraw or modify those aspects of the law that go exclusively to SPS purposes, such as the protection of health (for instance, procedures for monitoring health risks)? For instance, a single statutory scheme might include a labeling requirement that ensures that consumers who have ethical beliefs concerning the suitability of GMO food are alerted to products containing GMOs (which serves ethical, or perhaps merely consumer-information goals) as well as a requirement that GMOs meet a certain level of safety for human consumption. The last requirement clearly goes to SPS purposes. Thus, one would imagine that in order to be WTO-consistent a non-SPS-complying statutory scheme would need to be amended to remove the last requirement in order to be WTO-compliant, even though the labeling requirement could still stand, because justifiable based on non-SPS objectives.

A difficult question might arise as to whether citizens would support a measure, given that it is now known to be only permissible for non-SPS purposes. There might be something to be said for requiring a government that wants to sustain a given legal framework exclusively for non-SPS purposes to go back to the legislature or the people as it were and ascertain whether there is sufficient support for the measure based on it serving exclusively non-SPS purposes. Thus, the values of administrative democracy ${ }^{20}$ may not entirely weigh in favor of permitting governments to avoid reenacting or enacting twice measures serving different purposes. Despite what is implied by the Panel's hypothetical, we could imagine that it would be the exception rather than the rule that a legislature would enact exactly the same measure based exclusively on non-SPS concerns as it did taking into account both SPS and non-SPS purposes. This being said, the Panel's justified appreciation of the risks of confusion and uncertainty where regulations have to be enacted twice or reenacted, should certainly be taken into account in assessing the 'reasonable period of time' for compliance, if indeed it is appropriate to expect a measure serving multiple purposes to be modified in light of a finding that it is impermissible to the extent that it serves SPS purposes but only to that extent.

20 We, of course, realize that not all WTO Members are democracies; yet many of the issues that have emerged in the policy debate concerning the legitimacy of WTO adjudication in the context of food safety relate to the interaction between the values underpinning SPS disciplines - especially the privileging of science and technocratic judgment - and those of democracy. For an extensive treatment of this issue, see Howse (2000). 
Finally, we note one anomalous feature of the interrelationship between WTO norms that this ruling brings to light: because of the additional feature of scientific justification in SPS, it may be more not less difficult under WTO law to justify a measure for apparently compelling purposes such as the protection of human life or health (the most compelling, according to the $\mathrm{AB}$ in EC-Asbestos and Brazil-Tyres) than purposes such as the ethical purposes understood under Article XX of the GATT, for instance, the protection of public morals. As understood by the Panel and the $\mathrm{AB}$ in US-Gambling, 'public morals' can include aspects of public morality important to a given society but not universally understood as compelling interests of the highest order (though some of these, such as human rights, may also be included obviously within 'public morals'). Banning nonkosher or nonhalal meat seems a lot easier, under the WTO framework, than banning purportedly tainted or poisonous meat. ${ }^{21}$ Reflection on these structural concerns may lead to a better appreciation of the degree of deference with which the requirements of scientific justification in SPS should be applied.

\section{The interpretation of Articles 5.1 and 5.7 of the SPS Agreement}

\subsection{Article 5.1 of the SPS Agreement}

The following extracts from the Panel's ruling are indicative of its approach to SPS 5.1 , including aspects of that approach that we shall suggest in our commentary are highly problematic.

7.2983 ... A Member can, subject to compliance with applicable requirements, choose whether to base an SPS measure on a relevant international standard in line with Article 3.1 or, alternatively, to avail itself of the qualified right not to do so provided in Article 3.3. In contrast, in cases where the relevant scientific evidence is insufficient, e.g., because none is available, a Member who wishes nonetheless to take a precautionary SPS measure could not meet the requirement in Article 2.2 to ensure that this measure 'is not maintained without sufficient scientific evidence'. This further strengthens our conviction that Article 5.7 should be viewed as a qualified exemption from the relevant obligation in Article 2.2, confirming the right of Members to take measures which are 'necessary for the protection of human, animal or plant life or health' in situations where the available scientific evidence is 'insufficient'. Therefore, while recognizing the existence of substantive differences between Articles 3.1 and 3.3, on the one

21 It might be objected, however, that this is less anomalous than it first appears. In the case of a ban for health reasons, the regulating Member is sending a message that the product is harmful to health, which may affect the market in third countries, if consumers believe such a negative signal. Where the food is banned for ethical religious reasons prevalent in a particular society, the behavior of consumers elsewhere who do not share those beliefs is likely to be unaffected. As an empirical matter, however, the banning of GMOs in Europe, to the extent it is understood to be because of health concerns, does not seem to have itself affected consumer attitudes in the US, at least not obviously so. 
hand, and Articles 2.2 and 5.7, on the other hand, we do not consider that these differences support Canada's view that Article 5.7 constitutes an exception to Article 2.2 in the nature of an affirmative defence.

7.2990 According to the Appellate Body, " "relevant scientific evidence” will be "insufficient" within the meaning of Article 5.7 if the body of available scientific evidence does not allow, in quantitative or qualitative terms, the performance of an adequate assessment of risks as required under Article 5.1 and as defined in Annex A to the SPS Agreement'. Thus, if a Member may provisionally adopt an SPS measure on the basis of available pertinent information in situations where the scientific evidence is insufficient for an adequate risk assessment, as required by Article 5.1 and as defined in Annex A(4), it makes sense to require, as the second sentence of Article 5.7 does, that that Member seek to obtain 'the additional information necessary' for such a risk assessment. Once a Member has obtained the additional information necessary for a risk assessment which meets the definition of Annex A(4), it will be in a position to comply with its obligation in Article 5.1 to base its SPS measure on a risk assessment which satisfies the definition of Annex A(4).

7.3041 We begin our analysis with Austria's Reasons document. In this document, Austria points to new scientific evidence which, according to Austria, raises uncertainty with respect to the potential risks related to MON 810 maize, in particular regarding the effects on non-target organisms and the development of resistance in insects. According to Austria, this new scientific evidence raises doubts with regard to the safety of MON 810 maize for human health or the environment.

7.3094 However, nothing in the Reasons document indicates that Austria carried out a new assessment of the alleged risks in the light of the scientific evidence mentioned by Austria. We recall in this connection that a risk assessment must evaluate the likelihood or probability of particular risks, or evaluate the potential for adverse effects on animal health arising from the presence of certain substances in food, beverages or feedstuffs. The Reasons document refers to possibilities of risks arising in respect of MON 810 maize, but it does not itself evaluate the potential for adverse health effects or the likelihood of the risk of establishment, entry or spread of a pest. For example, Austria notes that reservations concern the '[p]ossible undesired effects of the Bt toxin on non-target organisms and the possible development of resistance in insects'. The document highlights studies of undesired effects on non-target organisms related to the consumption of $\mathrm{Bt}$ maize but does not itself make an evaluation of the potential for adverse health effects or the likelihood of these undesired effects occurring in the event that MON 810 maize were to be introduced. The Reasons document 
also identified one study which noted that 'further effects on the food chain [of consumption of Bt pollen by monarch butterflies] are possible'. Yet, there is no evaluation of the potential for adverse health effects or the likelihood of such effects occurring.

7.3095 Furthermore, we note that with respect to one of the risks identified in the Reasons document, namely the development of resistance to Bt toxin in insects, the Reasons document states that '[t]he risk for related groups of insects [...] cannot be assessed conclusively based on the available data'. This statement further confirms that Austria did not 'evaluate' or 'assess' the alleged risk.

7.3096 Accordingly, we are of the view that the Reasons document does not meet the definition of a risk assessment as provided in Annex A(4). We therefore consider that the Reasons document cannot be considered a risk assessment within the meaning of Annex A(4) and Article 5.1.

7.3097 We now turn to the scientific studies referred to by Austria in its Reasons document. Each of these studies describes aspects of Bt toxin impacts on insects. The study by Losey, entitled 'Transgenic pollen harms monarch larvae', describes results from a laboratory experiment in which monarch butterfly caterpillars were fed Bt maize pollen. The study focuses on a variety of Bt maize other than MON 810 maize. Furthermore, while the Losey study notes that results on larvae consumption and growth rates have 'potentially profound implications for the conservation of monarch butterflies' there is no attempt to evaluate these potential implications, rather the study notes that the experimental results point to possible environmental outcomes. For example, in arguing that monarch butterfly caterpillars are at risk from the production of Bt maize, the study states that ' $[\mathrm{t}]$ he large land area covered by corn in this region suggests that a substantial portion of available milkweeds may be within range of corn pollen deposition'. Hence, we do not consider that the Losey study in itself constitutes a risk assessment within the meaning of either the first or the second clause of Annex A(4) and Article 5.1.

7.3098 The second study, by Hilbeck et al., on '[t]oxicity of Bacillus thuringiensis Cry $1 \mathrm{Ab}$ Toxin to the Predator Chrysoperla carnea (Neuroptera: Chrysopidae)' described a feeding study in which insects were fed a liquid diet containing Bt toxins, rather than being fed Bt plants directly. Thus, we do not consider that this study evaluated the potential for adverse effects associated with the insects eating MON810 maize plants. In addition, in its conclusion it notes that 'trials investigating predation efficiency and predator performance under field conditions are necessary before conclusions regarding the potential ecological relevance of the results presented [...] can be drawn'. Hence, like the Losey study, the study by Hilbeck et al. does not evaluate the likelihood of an outcome in the field. Accordingly, as with the Losey study, we do not consider that the Hilbeck et al. study in itself constitutes a risk assessment within the meaning of either the first or the second clause of Annex A(4) and Article 5.1, although we accept that it may be of relevance for a risk assessment. 
7.3099 The third study, also by Hilbeck et al., concerns '[e]ffects of transgenic Bacillus thuringiensis corn-fed prey on mortality and development time of immature Chrysoperla carnea (Neuroptera: Chrysopidae)'. This study used a maize hybrid containing a gene from Bacillus thuringiensis. The study provides information regarding the impact on non-maize eating insects of eating herbivorous insects raised on Bt maize and thus is aimed at evaluating non-target impacts of Bt crop cultivation. While this study concludes that, in this experiment, differences in mortality exist for insect predators fed prey raised on $\mathrm{Bt}$ versus non-Bt maize, the study notes that ' $[\mathrm{n}] \mathrm{o}$ conclusions can be drawn at this point as to how results from [...] laboratory trials might translate in the field'. This statement, in our view, implies that this study per se cannot be said to evaluate the alleged risks identified by Austria in its Reasons document. In addition, given the lack of conclusions concerning how the laboratory trials might translate in the field noted above, we do not consider that the second Hilbeck study provides an evaluation of the potential for adverse effects on insect health from the presence of Bt toxin in food or feedstuffs. Therefore, we do not consider that this study in itself constitutes a risk assessment within the meaning of either the first or the second clause of Annex A(4) and Article 5.1, although we accept that it may be of relevance for a risk assessment.

7.3100 Finally, we recall that the European Communities provided as evidence a study by Austria on toxicological and allergological risks related to biotech products (the March 2003 document). As we noted above with respect to T25 maize, we consider that this study evaluates risk assessment procedures, and not the potential for adverse effects on human or animal health arising from the consumption of specific foods containing or consisting of GMOs. We therefore think that this March 2003 study does not constitute a risk assessment within the meaning of Annex A(4) and Article 5.1.

7.3101 In the light of the foregoing, we conclude that the above-mentioned documents relied on by Austria to justify its safeguard measure are not risk assessments within the meaning of Annex A(4) and Article 5.1.

7.3150 The final study, by the Öko-Institut e.V., provides an overview of the types of antibiotics which could be affected by the possible development of resistance to antibiotics due to the use of antibiotic resistance marker genes in transgenic plants. The study describes the therapeutic importance of a variety of antibiotics, but does not evaluate the likelihood that the consumption of transgenic plants in general, much less of Bt-176 maize specifically, will lead to the spread of diseases due to the development of resistance to the relevant antibiotics. The authors state that 'the wide dispersal of [antibiotic resistance] genes via agriculture, animal feeding and in the human food chain provides an additional path for the development of antibiotic resistance' and that 'this risk is not negligible' as outside hospitals the resistance problem was still smaller. The study further states that 'particularly worrying' is the fact that 'there are indications' that the transfer rate of antibiotic resistance in soils can be furthered by herbicide 
use. The study goes on to say that because herbicide applications are the rule in agriculture and because many ARMG in transgenic plants were transferred together with herbicide resistance genes, this 'possibly creates conditions which could [...] have a promoting influence on the development of resistance'. The study therefore recommends that ARMG should not be used any more.

7.3151 Hence, the study by the Öko-Institut asserts that there is a potential for adverse effects on human or animal health from the presence of ARMG in transgenic plants used as or in food/feed. However, it does not 'evaluate' that potential. Indeed, the study devotes only a few paragraphs to transgenic plants containing ARMG as an additional source of possible development of antibiotic resistance. Moreover, the study does not evaluate the likelihood of spread of diseases due to the presence of ARMG in transgenic plants. As indicated, the study refers to possibilities, but it does not determine likelihoods. We therefore do not consider that this study meets the definition of a risk assessment as provided in Annex A(4).

\subsubsection{Commentary}

As can be seen, the EU/Austria and Germany notably argued that even though the risk assessment conducted in the context of the EU-level approvals process had resulted in a negative determination, its safeguards were nevertheless consistent with the obligation to base its measures on a risk assessment, in that subsequent scientific studies and opinions had cast doubt on the adequacy of the earlier risk assessment. Here, the EU relied on the important jurisprudential principle established by the $\mathrm{AB}$ in EC-Hormones that Members when faced by diversity or divergence of scientific views, may rely on minority or nonmainstream scientific views. Thus, a Member might be entitled to regulate in relation to a perceived risk even where the mainstream view as embodied in a risk assessment suggests that this risk is negligible or nonexistent, where nonmainstream or minority scientific views suggest divergence from the mainstream scientific conclusions. As Eliason (2008) observes, in EC-Biotech there were some instances where the alternative scientific views presented by the EU/Austria and/or Germany did indeed constitute scientifically significant challenges to the adequacy of the earlier risk assessment, and other instances where this was not the case. Thus, where the alternative scientific studies contributed little in the case of T-25 Maize, with respect to bt176 Maize the scientific studies were more suggestive of risk-assessment problems (Eliason, 2008: 31ff.).

The Panel here took a very narrow view of the AB's remarks in EC-Hormones, suggesting that in order to rely on a divergent or minority opinion, the opinion would either have to be part of the original risk assessment, or embedded in some other risk assessment that on its own fulfilled all the requirements in SPS Annex A4 for risk assessment. This limitation has no ground, however, either in the text of the SPS agreement or in the reasoning of the AB. It introduces a superfluous formalistic procedural constraint on a Member's right to regulate, which is at odds with the very nature of scientific inquiry, where knowledge is advanced through a 
continuous process of scientists questioning and engaging with the previous work of their colleagues, a kind of competitive marketplace of ideas.

As Crawford-Brown, Pauwelyn, and Smith (2004) state: 'An important aspect of science is that it is by nature progressive, with methods designed to approach a better understanding over time.' This, the notion that a Member would have to ignore scientific evidence in the regulatory process because of its form as criticism or questioning of earlier studies, i.e. because the criticism is not itself a selfstanding risk assessment, is absurd. Moreover, in the hyper-proceduralist aspect of this interpretation, one can find traces of an approach to the meaning of basing a measure on a risk assessment that was explicitly rejected by the $\mathrm{AB}$ in overruling the Panel in EC-Hormones I. As the AB emphasized there, the requirement of basing a measure on risk assessment is not an actual procedural antecedent condition for enactment of a regulation. Instead, it is a substantive objective test of whether there is some kind of reasonable relation between the scientific evidence as it exists at the time the matter is being considered by the Panel and the measure as it is maintained. In fact, as Eliason (2008: 25ff.) notes, the Panel in EC-Biotech actually introduced a temporal limit on the scientific studies that could be considered, limiting these to studies that existed at the time the Panel was struck. This decision is questionable in that the SPS Agreement provides no textual support for any such limit (and nor does the DSU). Also, it has adverse consequences for the efficiency of the dispute settlement process. In effect, even if at the time the Panel decides, it turns out that a Member's measure is 'based on' a risk assessment within the meaning of 5.1, where this is the case because of scientific studies post-Panel establishment; in such an instance, the Panel will have to blind itself to this information, find a violation, only for the Panel to be reconvened months later as a 21.5 Panel so that it is able to find that the defending Member is now in conformity with 5.1.22

22 Perhaps the Panel's approach could be understood as a misguided attempt to prevent opportunistic use of 'junk science' ex post a dispute-settlement challenge to provide a scientific pretext for protectionist measures - misguided because there are other provisions of SPS that must be satisfied even where regulation is based on SPS Article 5.7. These requirements include:

Members should, when determining the appropriate level of sanitary or phytosanitary protection, take into account the objective of minimizing negative trade effects. (SPS Article 5.4)

With the objective of achieving consistency in the application of the concept of appropriate level of sanitary or phytosanitary protection against risks to human life or health, or to animal and plant life or health, each Member shall avoid arbitrary or unjustifiable distinctions in the levels it considers to be appropriate in different situations, if such distinctions result in discrimination or a disguised restriction on international trade. Members shall cooperate in the Committee, in accordance with paragraphs 1, 2 and 3 of Article 12, to develop guidelines to further the practical implementation of this provision. In developing the guidelines, the Committee shall take into account all relevant factors, including the exceptional character of human health risks to which people voluntarily expose themselves. (SPS Article 5.5)

Conformity with SPS provisions, including Article 5.7, will also not 'save' an SPS measure that is protectionist, in any case, because Article 5.7 is not a defense or exception to Article III:4 of the GATT. 


\subsection{Article 5.7 of the SPS Agreement}

The approach of the Panel, including aspects that we shall challenge in the commentary that follows, is indicated in the following extracts from the Panel Report: $:^{23}$

7.3242 There can be no doubt that a Member's appropriate level of protection is relevant to determining the SPS measure to be applied, if any, to protect that Member from risks. Article 5.3 of the SPS Agreement refers to the determination of 'the measure to be applied for achieving the appropriate level of sanitary or phytosanitary protection from ... risk', and Article 5.6 relates to the establishment or maintenance of '[SPS] measures to achieve the appropriate level of sanitary or phytosanitary protection'.

7.3243 In contrast, the definition of the term 'risk assessment' in Annex A(4) does not indicate that a Member's appropriate level of protection is pertinent to an assessment of the existence and magnitude of risks. Also, Annex A(5) to the SPS Agreement states that the concept of the appropriate level of protection is referred to by some Members as the concept of the 'acceptable level of risk'. We do not think that scientists need to know a Member's 'acceptable level of risk' in order to assess objectively the existence and magnitude of a risk. Furthermore, neither Article 5.2 nor Article 5.3 suggests that a Member's appropriate level of protection may be relevant to the assessment of risks. (footnotes omitted)

7.3058 The Panel notes that in EC-Hormones, the Appellate Body observed that a ' $[r]$ isk assessment could set out both the prevailing view representing the 'mainstream' of scientific opinion, as well as the opinions of scientists taking a divergent view'. ${ }^{24}$ It then went on to state that 'responsible and representative governments may act in good faith on the basis of what, at a given time, may be a divergent opinion coming from qualified and respected sources. By itself, this does not necessarily signal the absence of a reasonable relationship between the SPS measure and the risk assessment, especially where the risk involved is lifethreatening in character and is perceived to constitute a clear and imminent threat to public health and safety, ${ }^{25}$

7.3059 It is important to recall that this statement related to a hypothetical situation where divergent views were expressed as part of, and in, the same risk assessment. In the case at hand, we are not aware, and have not been made aware, of any divergent views that would be expressed in the risk assessments of the lead CA and SCP concerning T25 maize. Therefore, we are presented here with a situation that is different from that described by the Appellate Body in EC-Hormones. Furthermore, we note that the contributions of the Panel's experts do not support the view that the potential risks arising from the deliberate

23 Footnotes in original, but with different numbering.

24 'Appellate Body Report, EC-Hormones, para. 194.'

25 'Appellate Body Report, EC-Hormones, paras. 193-194.' 
release of T25 maize and the other biotech products subject to this dispute can be considered to be risks that are 'life-threatening in character' or that 'constitute a clear and imminent threat to public health and safety'. ${ }^{26}$

7.3067 We note the European Communities' argument that 'based on' does not mean 'conform to'. To the extent the European Communities means to argue that Members are free to adopt any kind of SPS measure provided there exists a risk assessment for the product subject to the SPS measure, we disagree. It is correct that the Appellate Body in EC-Hormones has said that the expression 'based on' as it appears in Article 3.1 of the SPS Agreement ${ }^{27}$ does not mean "conform to". ${ }^{28}$ However, the Appellate Body also said in EC-Hormones that in the specific context of Article 5.1, the expression 'based on' should be interpreted to mean 'sufficiently warranted by', 'reasonably supported by' or 'rationally related to'. ${ }^{29}$ As we have said, in the case of Austria's safeguard measure on T25 maize, there exists no apparent rational relationship between that measure, which imposes a complete prohibition, and risk assessments which found no evidence that T25 maize presents any greater risk to human health or the environment than its conventional (non-biotech) counterpart. ${ }^{30}$ At any rate, if we were to allow Austria effectively to ignore favourable risk assessments, we would turn these assessments into documents without any substantive importance and the conduct of these assessments into a mere formality. Yet, the requirement in Article 5.1 to 'base' an SPS measure on a risk assessment is plainly a substantive requirement, and not simply a formal requirement to accompany an SPS measure by a risk assessment. ${ }^{31}$

$\cdots$

7.3259 We recall that Austria adopted its safeguard measure on T25 maize in April 2000. Following Austria's notification of the measure, the Commission requested the SCP to analyse the information provided by Austria in support of its measure in order to determine whether this information would cause the SCP to consider that the product constituted a risk to human health or the environment. The SCP in its opinion of November 2000 concluded that the information provided by Austria did not constitute new scientific information which would change the original risk assessment which it had carried out in the context of the

26 'Ibid.'

27 'Article 3.1 states in relevant part that "Members shall base their [SPS] measures on international standards, guidelines or recommendations, where they exist ...".'

28 'Appellate Body Report, EC-Hormones, para. 166.'

29 'Ibid., para. 193.'

30 'We note that the Appellate Body in EC-Hormones confronted a comparable situation. Specifically, the Appellate Body found that scientific reports which concluded that the use of certain hormones for growth promotion purposes was safe did not rationally support an import prohibition maintained by the European Communities. Appellate Body Report, EC-Hormones, paras. 196-197.'

31 'We note that the Appellate Body in EC-Hormones also characterized the requirement that an SPS measure be "based on" a risk assessment as a "substantive requirement". Appellate Body Report, EC-Hormones, para. 193.' 
EC approval procedure concerning T25 maize. ${ }^{32}$ Thus, as we understand it, the SCP effectively reviewed its original risk assessment in the light of the information presented by Austria and confirmed its original risk assessment. ${ }^{33}$

7.3260 We have found above that both the SCP opinions delivered in the context of relevant EC approval procedures - the original assessments - and the SCP opinions delivered after the adoption of the relevant member State safeguard measures - the review assessments - are risk assessments within the meaning of Annex A(4) and Article 5.1 of the SPS Agreement. ${ }^{34}$ We recall in this regard that the European Communities does not suggest otherwise. ${ }^{35}$ In the light of this, we agree with the Complaining Parties that the SCP's review assessment of T25 maize, and the SCP's original assessment of T25 maize (which, as noted, was confirmed by the SCP's review assessment), serves to demonstrate that at the time of adoption of the Austrian safeguard measure, the body of available scientific evidence permitted the performance of a risk assessment as required under Article 5.1 and as defined in Annex A(4). We consider, therefore, that the Complaining Parties have established a presumption that Austria's safeguard measure was imposed in respect of a situation where relevant scientific evidence was not insufficient. This presumption has not been effectively rebutted by the European Communities. $^{36}$

\subsubsection{Commentary}

A central finding in the Panel's treatment of SPS 5.7 is that a Member cannot rely on 5.7 to sustain its regulations if there is 'sufficient scientific evidence' to

32 'Exhibits US-56; CDA-77 and 87; ARG-45 and ARG-46.'

33 'Exhibits US-56 (referencing original SCP assessment); CDA-75 and -87; ARG-45 and -46 (referencing original SCP assessment).'

34 'We recall that the review assessments are generally in the nature of supplemental assessments and thus need to be read in conjunction with the original assessments.'

35 'It is pertinent to recall in this context that in defending the Austrian safeguard measure against the Complaining Parties' claims under Article 5.1, the European Communities essentially argued that Austria acted on the basis of new scientific information which presented a view divergent from the mainstream scientific opinion reflected in the original risk assessment. It may be that in making this argument the European Communities meant to refer to the SCP's original risk assessment. However, the fact that Austria may have disagreed with the SCP's original assessment, and possibly also with the SCP's subsequent review assessment, would not imply that the SCP's review and original assessments are not risk assessments as required under Article 5.1 and as defined in Annex A(4). The Appellate Body has made it clear that a risk assessment as required under Article 5.1 " [c] ould set out both the prevailing view representing the 'mainstream' of scientific opinion, as well as the opinions of scientists taking a divergent view." Appellate Body Report, EC-Hormones, para. 184. Thus, the mere fact that the scientists taking a divergent view do not agree with the majority view does not necessarily mean that the majority view is based on a risk assessment which does not meet the standard and definition set out in Annex A(4). In any event, as noted, the European Communities does not argue that the SCP's original and review assessments of T25 maize are not risk assessments as required under Article 5.1 and as defined in Annex A(4).' We note that in its recent ruling in United States-Continued Suspension of Obligations in the EC-Hormones Dispute (WT/DS320/AB/R, 16 October 2008), the AB has strongly reaffirmed its remarks in the original EC-Hormones ruling concerning minority scientific opinion (para. 677).

36 'In view of this finding, it is not necessary to revisit the issue of whether, given its multiple purposes, the Austrian safeguard measure should be treated as constituting one or more SPS measures. Thus, like the Parties, we will continue to treat this measure as constituting one single SPS measure.' 
conduct a risk assessment within the meaning of SPS 5.1. In such a case, the Member must base its measure on a risk assessment within the meaning of 5.1. According to the Panel, in the case of the member-state safeguards, since in each instance a risk assessment had been conducted, ipso facto the Member could not rely on 5.7. The historical fact of a risk assessment established that this was a case where sufficient scientific evidence existed to base the measure on a risk assessment.

This interpretation is at once a reflection of a misunderstanding of the role of risk assessment in the advancement of scientific knowledge, as well as of the role of 'precaution' and the precautionary principle in 5.7. First of all, it is a very unlikely situation that responsible scientists would pronounce that it is a priori impossible to conduct a risk assessment because of insufficiency of scientific evidence. Modern science is learning by trial and error. Thus, the limits of the scientific evidence would most likely come to light by attempting a risk assessment using conventional methodologies. On the Panel's approach, in order to invoke 5.7, a Member would have to show that no risk assessment has been attempted; once there is a risk assessment, no matter to what extent that very assessment exercise reveals the limits of the evidence as a basis for deciding regulatory choices, there is no right to proceed in a precautionary manner under 5.7. However, in its recent decision in the case of United States - Continued Suspension of Obligations in the EC-Hormones Dispute (WT/DS320/AB/R, 16 October 2008), the Appellate Body has now taken a different view than that of the Panel in EC-Biotech on this issue. According to the AB, "WTO Members should be permitted to take a provisional measure where new evidence from a qualified and respected source puts into question the relationship between the pre-existing body of scientific evidence and the conclusions regarding the risks. We are referring to circumstances where new scientific evidence casts doubts as to whether the previously existing body of scientific evidence still permits of a sufficiently objective assessment of risk' (para. 703).

As Eliason (2008) pointedly notes, what comes to light in the attempt to assess risk in the EC-Biotech matter is precisely that laboratory experiments are not sufficient to predict with any real degree of certainty the incidence of some of the risk that are, and should be, of most concern to regulators. Thus, the conclusion to be drawn from existing risk assessment is the insufficiency of scientific evidence. But sufficient evidence would require large-scale field trials, which themselves are dangerous. As she suggests:

The Panel found that under the criteria established by the AB in AustraliaSalmon, none of the documents submitted by Germany constituted a risk assessment, and that the scientific studies cited 'failed to evaluate the potential or likelihood of the occurrence of the adverse effect' identified in the Reasons document. Despite the indication of the studies that there might be potential risks, the preliminary nature of those studies means that scientifically, an evaluation of the likelihood of the occurrence would have been premature without 
further testing. The Panel failed to identify here or elsewhere in EC-Biotech what level of evaluation of potential or likelihood of the occurrence of the adverse effect would be sufficient for a risk assessment. It would be beneficial for future cases if the guidelines for what the sufficient level is in the eyes of the Panel and Appellate Body were made clearer. In this case, while the mere existence of the possibility of a risk means that under scientific testing procedures, large-scale field tests would be discouraged, further limited field testing was explicitly encouraged at the conclusion of each of the studies, opening an avenue for an Article 5.7 argument of insufficiency of scientific evidence in support of the temporary safeguard measure. (Eliason, 2008: 41)

\section{Concluding remark}

Rather than trying to summarize our diverse observations on the EC-Biotech dispute, or to negotiate among the two of us a joint view concerning the appropriateness of the outcome of the dispute, we end by pointing to an aspect of the dispute to which we have alluded in our introductory remarks - the Herculean task facing the Panel. The enormous work the Panel had to undertake is reflected in the monumental size of the Panel Report: the Table of Contents runs over almost 40 pages, the main body comprises over 1000 pages, and in addition there is a huge set of Appendices, etc. Panels rarely complain over their workloads, but the EC-Biotech Panel complains bitterly (7.37-7.45). Listing the large number of difficulties it had to deal with, it mentions that the parties submitted over 3100 documents, some of which contained more than 100 pages. The Panel also bitterly criticizes the parties, and in particular the EC, for adding new information late during the dispute process, and for presenting it in a format that is difficult for the Panel to assess. It also complains about the three complaining parties' lack of coordination of their argumentation or submissions. Add to this the inherent complexity of the legal, conceptual, and scientific issues it had to address, and it is obvious that any critique against the Panel's determination must be accompanied with an acknowledgment of the impossible task it faced. This fact does not make a questionable determination correct, but it should serve to place any perceived shortcomings in context.

Most importantly, EC-Biotech raises the fundamental question of what are the limits of the issues that should be addressed by the dispute settlement system? It has been said before, but it deserves repetition: the system will not easily take the strain of having to decide matters that are viewed by Members as only determined legitimately by 'politics'. To take just one example, what would it do to the credibility of the system if it were to rule on the safety of nuclear power?

\section{References}

Bail, Christoph, Robert Falkner, and Helen Marquard (eds.) (2002), The Cartagena Protocol on Biosafety: Reconciling Trade in Biotechnology with Environment and Development? London: RIIA/Earthscan. 
Breyer, Stephen (1993), Breaking the Vicious Circle: Toward Effective Risk Regulation, Cambridge, MA: Harvard University Press.

Crawford-Brown, Douglas, Joost Pauwelyn, and Kelly Smith (2004), 'Environmental Risk, Precaution, and Scientific Rationality in the Context of WTO/NAFTA Trade Rules', Risk Analysis, 24(2): 461-469.

Eliason, Antonia (2008), 'Science versus Law in the WTO Jurisprudence - The (Mis)interpretation of the Scientific Process and the (In)sufficiency of Scientific Evidence in EC-Biotech', unpublished manuscript, World Trade Institute, Berne.

Horn, Henrik and Petros C. Mavroidis (2004), 'Still Hazy After All These Years: The Interpretation of National Treatment in the GATT/WTO Case-law on Tax Discrimination', European Journal of International Law, 15(1): 39-69.

Horn, Henrik and Joseph H. H. Weiler (2003), 'European Communities - Measures Affecting Asbestos and Asbestos-Containing Products', in Henrik Horn and Petros C. Mavroidis (eds.), The WTO Case Law of 2001 - The American Law Institute Reporters' Studies, Cambridge: Cambridge University Press.

Howse, Robert L. (2000), 'Democracy, Science, and Free Trade: Risk Regulation on Trial at the World Trade Organization', University of Michigan Law Review, 98(7): 2329-2357.

Howse, Robert L. (2008), 'The Use and Abuse of International Law in WTO Trade/Environment Litigation', in Merit E. Janow et al. (eds.), The WTO: Governance, Dispute Settlement and Developing Countries, Geneva/Huntington, NY: World Trade Organization/Juris Publishing, pp. 635-670.

Howse, Robert L. and Donald H. Regan (2000), 'The Product/Process Distinction: An Illusory Basis for Disciplining “Unilateralism” in Trade Policy', European Journal of International Law, 11(2): 249-289.

Howse, Robert L. and Elisabeth Türk (2006), ‘The WTO Impact on Internal Regulations: A Case Study of the Canada-EC Asbestos Dispute', in George A. Bermann and Petros C. Mavroidis (eds.), Trade and Human Health and Safety, Columbia Studies in WTO Law and Policy, New York: Cambridge University Press, pp. 77-117; reprint of previously published work.

Pauwelyn, Joost (2003), Conflict of Norms in Public International Law: How WTO Law Relates to Other Rules of International Law, Cambridge Studies in International and Comparative Law, New York: Cambridge University Press.

Regan, Donald H. (2006), "Regulatory Purpose and "Like Products" in Article III:4 of the GATT (with Additional Remarks on Article III:2)', in George A. Bermann and Petros C. Mavroidis (eds.), Trade and Human Health and Safety, Columbia Studies in WTO Law and Policy, New York: Cambridge University Press, pp. 190-223.

Trebilcock, Michael J. and Robert L. Howse (2005), The Regulation of International Trade, London: Routledge, 1995; second edition, 1999; third edition, 2005. 